\title{
Evaluación de microorganismos eficientes en la producción de plántulas de tomate (Solanum lycopersicum L.)
}

\author{
Evaluation of efficient microorganisms in the tomato seedling production \\ (Solanum lycopersicum L.)
}

\section{Alexander Calero H. ${ }^{1}$; Elieni Quintero R. ${ }^{2}$, Yanery Pérez D. ${ }^{3}$; Dilier Olivera V. ${ }^{4}$; Kolima Peña C. Iván Castro L. ${ }^{6}$; Janet Jiménez H. ${ }^{7}$}

1 M.Sc. Agricultura Sostenible. Universidade Estadual Paulista “Júlio de Mesquita Filho" (UNESP). São Paulo, Brasil. alexcalero34@gmail.com.

2 Investigadora. I.A. Empresa Agropecuaria Agroindustrial “Melanio Hernández”. Sancti Spíritus, Cuba. elieni.quintero@ gmail.com.

3 Profesora. Licenciada en Derecho. Centro Universitario Municipal de Taguasco, Universidad de Sancti Spíritus “José Martí Pérez". Sancti Spíritus. Cuba. yanery@uniss.edu.cu

4 Profesor. Ph.D. Ciencias Agrícolas. Universidade Estadual Paulista “Júlio de Mesquita Filho" (UNESP). São Paulo, Brasil. dilierolvi@gmail.com

5 Profesora. M.Sc. Agricultura Sostenible. Universidad de Sancti Spíritus “José Martí Pérez”. Sancti Spíritus, Cuba. kolimapena@gmail.com

6 Profesor. Ph.D. Ciencias Agrícolas. Universidad Agraria de la Habana “Fructuoso Rodríguez". Mayabeque. Cuba. ivanc@ unah.edu.cu

7 Profesora. Ph.D. Universidad de Sancti Spíritus “José Martí Pérez”. Sancti Spíritus, Cuba. janet@uniss.edu.cu

Citar: Calero, A., Quintero, E., Pérez, Y., Olivera, D., Peña, K., Castro, I. \& Jiménez, J. (2019). Evaluación de microorganismos eficientes en la producción de plántulas de tomate (Solanum lycopersicum L.). Revista de Ciencias Agrícolas. 36(1): 67-78 doi: doi: http://dx.doi.org/10.22267/rcia.193601.99

Recibido: julio 13 de $2018 . \quad$ Aceptado: febrero 27 de 2019.

\section{RESUMEN}

Los principales problemas de la producción de plántulas de tomate en las regiones tropicales residen principalmente por la afectación de los factores climatológicos y el bajo empleo de los biofertilizantes, por lo cual, es importante buscar alternativas eficientes de manejo de los biofertilizantes en estas 
regiones que aumente la racionalidad y sustentabilidad. El objetivo del trabajo fue evaluar diferentes formas de aplicación de microorganismos en la producción de plántulas de tomate. El diseño fue en Bloques al Azar, en esquema factorial 4x3, el tamaño de las parcelas fue de $2 \mathrm{~m}^{2}$ y los factores de estudios fueron la aplicación de microorganismos eficientes en cuatro niveles: sin (0), inoculación de la semilla a $100 \mathrm{~mL} \mathrm{~L}^{-1}(\mathrm{~S})$, aplicaciones foliares a $100 \mathrm{~mL} \mathrm{~L}^{-1}(\mathrm{~F})$ y la inoculación a la semilla más aplicaciones foliares $(\mathrm{S}+\mathrm{F})$ y tres variedades (Amalia, Rilia y Seen-2), con tres repeticiones. Los descriptores evaluados fueron el porcentaje de germinación (\%), diámetro del tallo $(\mathrm{cm})$, altura de planta $(\mathrm{cm})$, número de hojas, rendimiento (plántulas $\mathrm{m}^{-2}$ ) y el ciclo de producción de las plántulas (días). Los resultados mostraron que en las tres variedades de tomate, la combinación de la inoculación a las semillas con las aplicaciones foliares de microorganismos eficientes incrementó el diámetro del tallo, la altura de la planta, el número de hojas y el rendimiento en las variedades Amalia y Rilia en 26,0 \% y en la Seen-2 un 25,0\% con relación al tratamiento control y el ciclo de producción de plántulas fue reducido en las variedades Amalia y Seen-2 un 24,0\% y en la Rilia un 22,0\%.

Palabras claves: Biofertilizantes, germinación, inoculación foliar, interacción, rendimiento, tratamiento de semillas.

\begin{abstract}
The main problems of the production of tomato seedlings in the tropical regions reside mainly by the affectation by climatic factors and the low use of biofertilizers, for which, it is important to look for efficient alternatives of biofertilizers management in these regions that increases the rationality and sustainability. The objective of the work was to evaluate different application forms of efficient microorganisms in the tomato seedlings production. The randomized block design was used, in a $4 \times 3$ factorial scheme, the plot size was $2 \mathrm{~m}^{2}$ and the studied factors were: the application of efficient microorganisms (EM) in four levels: sin (0), seed inoculation at $100 \mathrm{~mL} \mathrm{~L}^{-1}(\mathrm{~S})$, foliar applications at $100 \mathrm{~mL} \mathrm{~L}^{-1}(\mathrm{~F})$ and the combination of seed inoculation with foliage applications $(\mathrm{S}+\mathrm{F})$ and three tomato varieties (Amalia, Rilia and Seen-2), with three replications. Were evaluated the fallowing indicators: the emergence percentage $(\%)$, stem diameter $(\mathrm{cm})$, plant height $(\mathrm{cm})$, number of leaves, yield (seedlings $\mathrm{m}^{-2}$ ) and the seedling production cycle (days). The results showed that, in the three tomato varieties, the combinate treatment of seeds inoculation with foliage applications of efficient microorganisms increased the stem diameter, plant height, number of leaves and yield in the Amalia and Rilia varieties by $26 \%$, and Seen- 2 by $25 \%$ with relation to the control and the seedling production cycle was reduced in Amalia and Seen-2 varieties by $24 \%$ and Rilia by $22 \%$.
\end{abstract}

Key words: biofertilizer, germination, foliage inoculation, interaction, yield, seed treatment

\section{INTRODUCCIÓN}

El tomate (Solanum lycopersicum L.) es uno de los cultivos vegetales más importante y más consumido en el mundo (Hernández et al., 2014; $\mathrm{Xu}$ et al., 2014). En Cuba, este cultivo ocupa aproximadamente el 36\% del área destinada a la siembra de hortalizas, con una producción de 266,30 miles de toneladas; es cultivada en todas las provincias del país, con un rendimiento promedio de 7,00 t ha-1 (Gómez et al., 2010). La facilidad de propagar el tomate por medio de semillas, hizo que la propagación vegetativa fuera poco explorada e investigada (Nadai et al., 2015). Las actividades de producción de plántulas deben ser supervisadas en todas las etapas del proceso, con el objetivo de entregar a los agricultores semillas ó plántulas con alta 
calidad (Pinheiro et al., 2017). La producción de plántulas de tomate puede ser sobre el suelo, arena y con sustratos (Gómez et al., 2010). Estos últimos son muy utilizados en la actualidad porque incrementan el número de hojas y la masa seca del tallo y de la parte aérea (De Mendonça et al., 2013).

En varios países, se aplican habitualmente biofertilizantes a los cultivos, preparados con microorganismos del género Rhizobium, Azospirillum, Bacillus y micorrizas. En países de América Latina como Colombia, Costa Rica, Cuba, Brasil, México, Nicaragua y Venezuela, existen bastas experiencias en la utilización de diferentes bioproductos que tienen como base para su funcionamiento a microorganismos nativos (Noh et al., 2014). Una de las posibles alternativas propuestas contra tal situación, es la biofertilización con microorganismos del suelo, los cuales, reproducidos en una mezcla, producen un efecto potencializado sobre los cultivos y otros procesos agropecuarios. Esta forma de reproducción, denominada tecnología de Microorganismos Eficientes (ME), ha sido investigada, desarrollada y aplicada en más de 80 países del mundo sobre una multitud de usos agropecuarios y ambientales (Arias, 2010). Otros autores refieren que el principio fundamental de esta tecnología consiste en la introducción de un grupo de microorganismos benéficos para mejorar las condiciones del suelo (Pedraza et al., 2010). Estudios recientes han reportados los efectos benéficos, porque su introducción ha favorecido y beneficiado a los agricultores (Luna y Mesa, 2016), varios estudios reportaron los efectos benéficos en la producción de plántulas de diferentes hortalizas (Liriano et al., 2015; Olivera et al., 2015; López et al., 2017a; Núñez et al., 2017).

La producción de plántulas de tomate de mesa sobre el suelo, es una práctica que utilizan la mayoría de los agricultores que se dedican al cultivo, la cual es afectada por factores climatológicos, alto empleo fertilizantes químicos y poco conocimiento de la utilización de los biofertilizantes, problemas que retrasan la calidad y el ciclo de producción de las plántulas, proporcionando afectaciones en la producción de tomate. Es conocido que la utilización de plántulas desde el establecimiento inicial del cultivo, es esencial para el éxito de la producción. La hipótesis a constatar es que la aplicación de microorganismos eficientes podría estimular y aumentar la producción de plántulas de tomate. Para comprobar esta hipótesis, el objetivo de esta investigación fue evaluar diferentes formas de aplicación de microorganismos eficientes en la producción de plántulas de tomate.

\section{MATERIALES Y MÉTODOS}

El trabajo se realizó en la Cooperativa de Crédito y Servicios "Humberto Castellano", ubicada

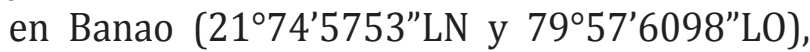
Sancti Spíritus, Cuba. Las variables climáticas fueron registradas por la Estación Provincial de Sancti Spíritus. La temperatura media diaria fue de $22,35^{\circ} \mathrm{C}$, la humedad relativa media diaria $77,50 \%$ y la precipitación pluvial acumulada de $19,50 \mathrm{~mm}$.

Las variedades de tomate Amalia, Rilia y Seen2, fueron obtenidas en la Empresa de Semillas de Sancti Spíritus, con un 97\% de germinación. La siembra se realizó de forma manual, en un semillero tradicional en canteros de $24,00 \mathrm{~m}$ de longitud y $1,00 \mathrm{~m}$ de ancho, la distancia de $0,15 \mathrm{~m}$ entre líneas y depositadas a chorrillo en el surco. Las siguientes atenciones culturales fueron realizadas según lo establecido en el instructivo técnico del cultivo (Gómez et al. 2010).

Diseño experimental. Se utilizó en diseño en Bloques al Azar con esquema factorial de 4x3, donde los factores fueron microorganismos eficientes (ME) con las modalidades control 
(sin aplicación), inoculación de la semilla $100 \mathrm{~mL} \mathrm{~L}^{-1}(\mathrm{~S})$, aplicaciones foliares a $100 \mathrm{~mL} \mathrm{~L}^{-1}$ (F) e inoculación a la semilla más aplicaciones foliares $(\mathrm{S}+\mathrm{F})$ y tres variedades (Amalia, Rilia y Seen-2), para un total de 12 tratamientos y tres repeticiones para formar 36 parcelas de $2 \mathrm{~m}^{2}$.

La inoculación de la semilla con ME fue realizada previa peletización antes de la siembra y los tratamientos foliares comenzaron a partir de los 7, 14 y 21 días después de la germinación (ddg).

Características del suelo. El tipo de suelo donde se ubicó el experimento, fue clasificado como Ferralítico Rojo Lixiviado, sobre esquistos de acuerdo con Hernández et al. (2015), Nitisol Ródico Éutrico según la IUSS (2015). Estos suelos, son muy evolucionados, de perfil ABtC, profundos con horizonte Bt argílico de color rojo a rojo amarillento y se caracteriza por tener propiedades níticas, con predominio de arcillas del tipo 1:1 y óxidos e hidróxidos de hierro y aluminio. La pendiente promedio, de todas las parcelas evaluadas no superó el 3\%, considerada como poco ondulada. Esta es una característica importante que se consideró en el diseño, pues en función de la pendiente, podría ser mayor o menor el grado de absorción de agua en los diferentes tratamientos.

Características de los microorganismos eficientes (ME). El inóculo de ME fue adquirido en la Sucursal de Labiofam de Sancti Spíritus, compuesto por Bacillus subtilis B/23-45-10 Nato (5,4 104ucf $\left.\mathrm{mL}^{-1}\right)$, Lactobacillus bulgaricum B/103-4-1 (3,6 104ucf $\left.\mathrm{mL}^{-1}\right)$ y Saccharomyces cereviciae L-25-7-12 (22,3 105ucf $\left.\mathrm{mL}^{-1}\right)$, con certificado de calidad emitido por ICIDCA, código R-ID-B-Prot-01-01, realizado según la metodología propuesta por Olivera et al. (2014) y caracterizado por López et al. (2017b), con las siguientes características: materia seca $17,0 \mathrm{~g} \mathrm{~L}^{-1}$, materia orgánica $1100,00 \mathrm{mg} \mathrm{L} \mathrm{L}^{-1}, \mathrm{pH} \quad 3,16$, nitrógeno amoniacal $\left(\mathrm{N}-\mathrm{NH}_{4}{ }^{+}\right) 0,03 \mathrm{mg} \mathrm{L}^{-1}$, potasio $\left(\mathrm{K}^{+}\right) 0,80 \mathrm{mg} \mathrm{L}^{-1}$, fosforo $\left(\mathrm{H}_{2} \mathrm{PO}_{4}^{-}\right) 0,83 \mathrm{mg} \mathrm{L}^{-1}$, calcio $\left(\mathrm{Ca}^{2+}\right) 24,05 \mathrm{mg} \mathrm{L}^{-1}$ y magnesio $\left(\mathrm{Mg}^{2+}\right) 4,86 \mathrm{mg} \mathrm{L}^{-1}$.
Variables evaluadas. Según Gómez etal.(2010) los criterios para definir la óptima calidad de las plántulas a los 25-30 días de germinada la semilla, con una altura de $10-12 \mathrm{~cm}$, de tres a cuatro hojas sanas y bien desarrolladas, grosor del tallo entre de 3 - $5 \mathrm{~mm}$, buen desarrollo de la raíz y color verde brillante. La evaluación de la emergencia de las semillas se realizó a los 10 días posteriores de la siembra en un área de $0,20 \mathrm{~m}^{2}$ y a los 25 días después de la germinación, se determinaron las siguientes variables: altura $(\mathrm{cm})$, diámetro $(\mathrm{cm})$, promedios de hojas por plántulas, rendimiento (plántulas $\mathrm{m}^{-2}$ ) y el ciclo de producción (ddg).

Análisis estadísticos. Los datos obtenidos fueron sometidos a un análisis descriptivo para variables cuantitativas, se determinó la distribución normal, el test de KolmogórovSmirnov para la bondad de ajuste y se aplicó la prueba Dócima de Levene para evaluar la homogeneidad de la varianza. Cuando existió normalidad y homogeneidad se realizó el Análisis de Varianza simple (ANDEVA). Cuando se encontró significancia a un $\alpha$ de 0,05 en las diferentes fuentes de variación, las medias fueron comparadas por la prueba de Rangos Múltiples de Tukey $(\mathrm{P}<0,05)$. Los datos fueron procesados en el software estadístico AgroEstat ${ }^{\circledR}$ (Barbosa y Maldonado, 2015).

\section{RESULTADOS Y DISCUSIÓN}

El tratamiento a las semillas con microorganismos eficientes ME, fue significativo en relación a los no inoculados con este biofertilizante (Figura 1). La emergencia de las semillas fue significativa $(P \leq 0,05)$ y aumentada con la inoculación de ME con relación a la no inoculación de semillas. Los mayores porcentajes fueron logrados en las variedades Amalia y Seen-2 comparadas con la Rilia.

Se evidencian efectos positivos de la inoculación a las semillas con $\mathrm{ME}$, con aumento de los 


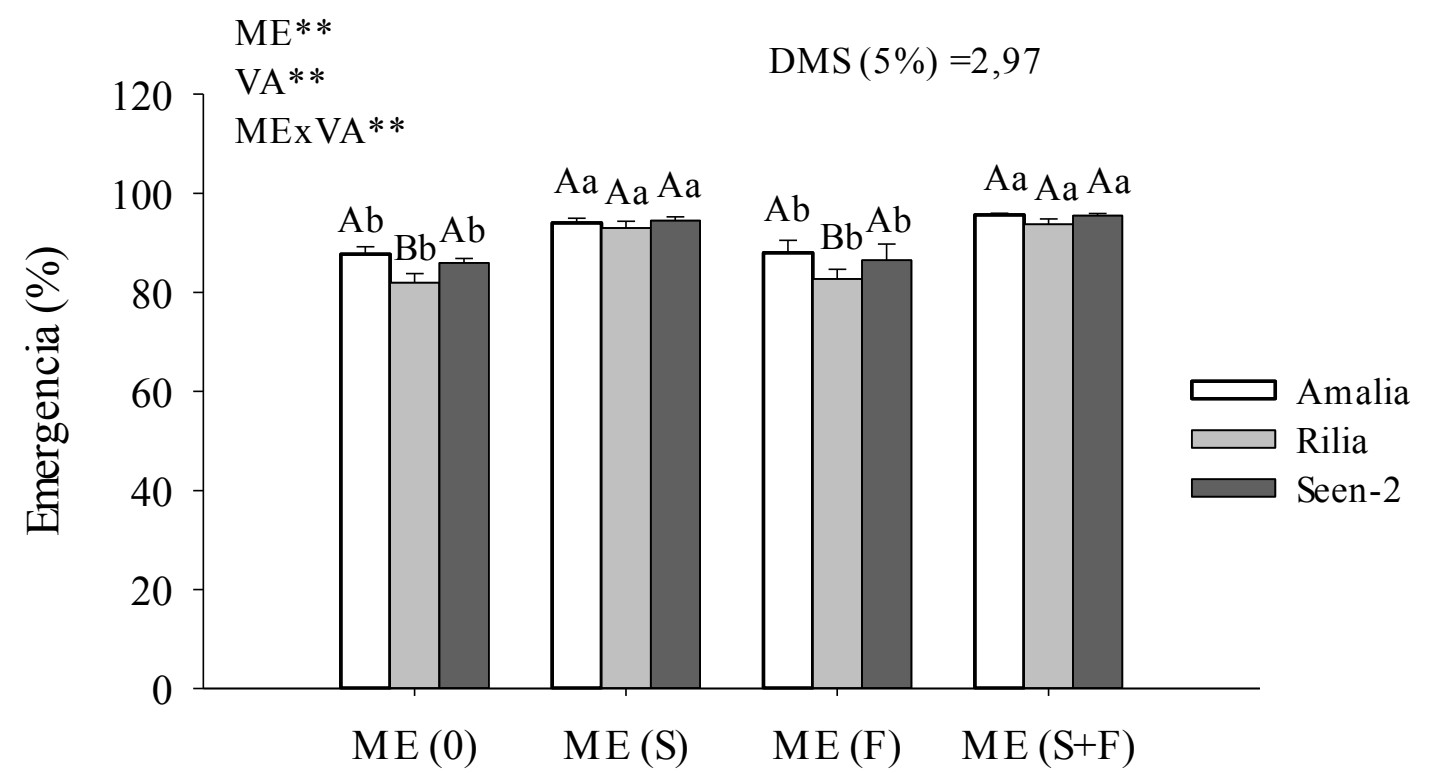

ME (0): sin aplicación; ME (S): inoculación a la semilla; ME (F), aplicaciones foliares; ME (S+F): inoculación a las semillas más aplicaciones foliares. Valores representados por las medias $(n=5) \pm$ desviación estándar (DE). Letras mayúsculas difieren entre variedades y letras minúsculas entre tratamientos, según Tukey $(\mathrm{P} \leq 0,05)$. ** Significativo al 99,00\% de confiabilidad.

Figura 1. Efecto de los tratamientos en el porcentaje de emergencia de las plántulas de tomate en las variedades Amalia, Rilia y Seen-2.

porcentajes de germinación en 7,92, 13,35 y $10,14 \%$ en las semillas de las variedades Amalia, Rilia y Seen-2, respectivamente con relación a las no inoculadas. Algunas investigaciones, han reportado que los ME, propician una mejor germinación y desarrollo de las plántulas, por ejemplo, en semillas de tomate Luna et al. (2013) reportaron que la inoculación con Bacillus firmus aumentó la germinación en 6,00\%, efecto que fue superado en este trabajo. También en este propio cultivo con la variedad Amalia, Olivera et al. (2015) reportaron incrementos del número de plantas por unidad de área entre 27,00 y $38,00 \%$, donde se aplicaron los microorganismos nativos con relación al control sin aplicación. Por otra parte, Szilagyi et al. (2015) obtuvieron que los tratamientos con Bacillus amyloliquefaciens subsp. plantarum, no alteraron significativamente el porcentaje de germinación en las semillas de dos cultivares de tomate, cuando fueron inoculadas con esta bacteria.

Se encontraron efectos significativos $(\mathrm{P} \leq 0,05)$ en lainteracción entre las formas de aplicación de ME y las variedades en cuanto al diámetro de las plántulas, uno de los indicadores que determina el momento del trasplante de las plántulas de tomate como ya fue relatado por Olivera et al. (2015). Todas las formas de utilización de los ME fueron significativas $(P \leq 0,05)$ y superiores en relación a la no utilización del biofertilizante (Figura 2), con destaque para la forma asociada de $\mathrm{ME}(\mathrm{S}+\mathrm{F})$ al aumentar el diámetro de las plantas en relación a las formas individuales de ME y superar al tratamiento sin aplicación en $150,00 \%$ para la variedad Amalia, $104,00 \%$ en la Rilia y $89,29 \%$ para la Seen-2. 


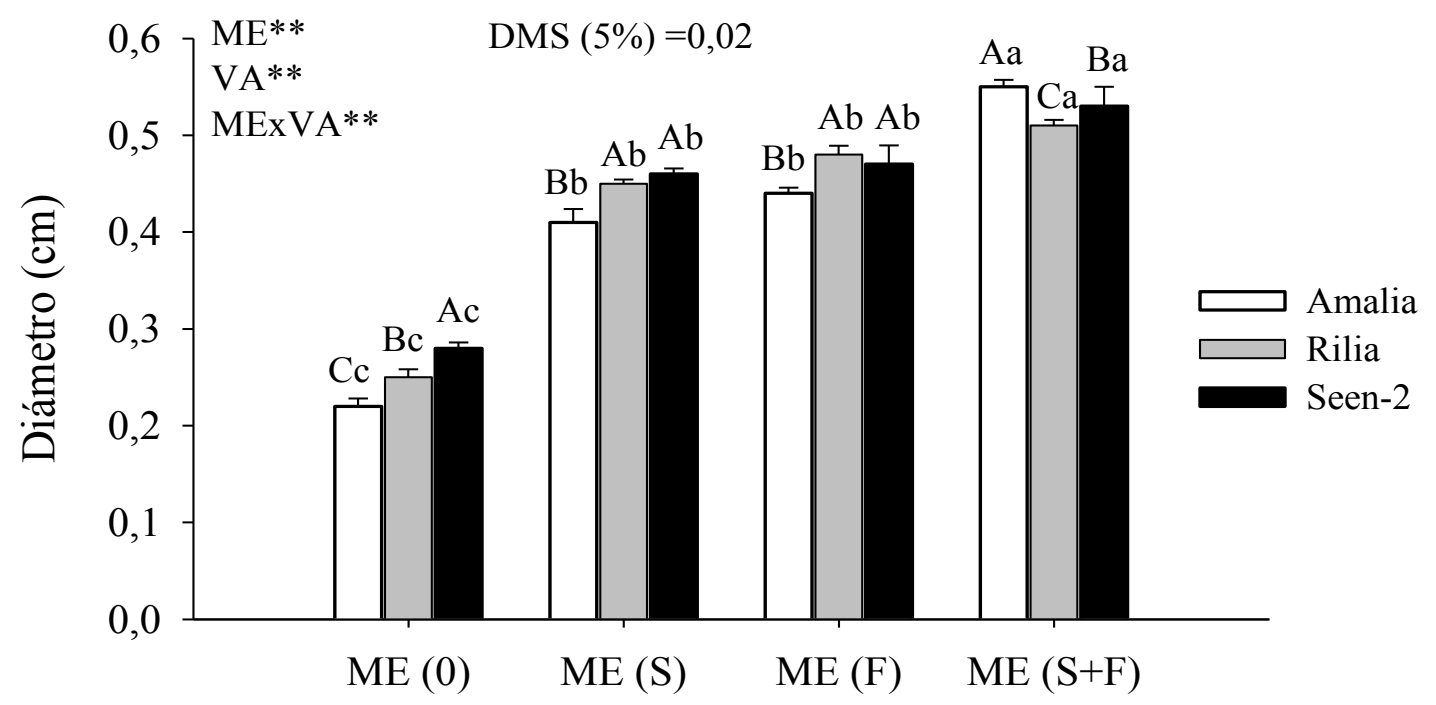

ME (0): sin aplicación; ME (S): inoculación a la semilla; ME (F), aplicaciones Foliares; ME (S+F): inoculación a las semillas más aplicaciones foliares. Valores representados por las medias $(n=5) \pm D E$. Letras mayúsculas difieren entre variedades y letras minúsculas entre tratamientos, según Tukey $(\mathrm{P} \leq 0,05)$. ${ }^{* *}$ Significativo al $99,00 \%$ de confiabilidad. Fuente: elaboración propia.

Figura 2. Efecto de los tratamientos en el diámetro de las plántulas de tomate en las variedades Amalia, Rilia y Seen -2.

La utilización de los ME de forma individual y combinada con Trichoderma harzianum incrementó el diámetro del falso tallo de plántulas de cebolla con respecto al tratamiento sin aplicación (Liriano et al., 2015). Resultados positivos en el incremento del diámetro de las plántulas de tomate fueron, relatados por Olivera et al. (2015) al incrementar en 67,03\% con la aplicación de ME a 50mL L-1 a los 7 y 14 ddg con relación al testigo sin aplicación.

La altura de las plántulas de tomate, presentó efectos significativos $(\mathrm{P} \leq 0,05)$ para la interacción entre ME y las variedades. Esta variable constituye un elemento definidor del momento óptimo del trasplante. Todas las formas de aplicación de $\mathrm{ME}$, fueron significativas $(\mathrm{P} \leq 0,05)$, porque incrementaronlaaltura delasplantas, con respecto al tratamiento no tratado en las tres variedades (Figura 3). Los resultados más significativos en el incremento de este indicador fueron logrados cuando se asoció microorganismos eficientes $(\mathrm{S}+\mathrm{F})$ comprados con las formas individuales de ME (S), ME (F) al aumentar el crecimiento de las plántulas de tomate en $62,0 \%$ en la variedad Amalia, 58,0\% en la Rilia y 65,0\% en la Seen- 2 en comparación con el tratamiento control, lo que evidenció un efecto estimulador de la aplicación de microorganismos eficientes como inoculante en semillas tomate y aplicaciones foliares en las plántulas.

Algunos investigadores han reportado, que la introducción de un grupo de microorganismos benéficos en el área de cultivo, mejoran las condiciones del suelo, suprimen la putrefacción (incluyendo enfermedades) y aumentan la eficacia del uso de la materia orgánica por las plantas (Pedraza et al., 2010). Resultados positivos en la producción de plántulas de cebolla, fueron logrados por Liriano et al. (2015) cuando se aplicó ME individual y combinada con T. harzianum, obteniendo una mayor calidad con incremento de la altura de las plantas cuando fueron comparadas con el tratamiento sin aplicación. 


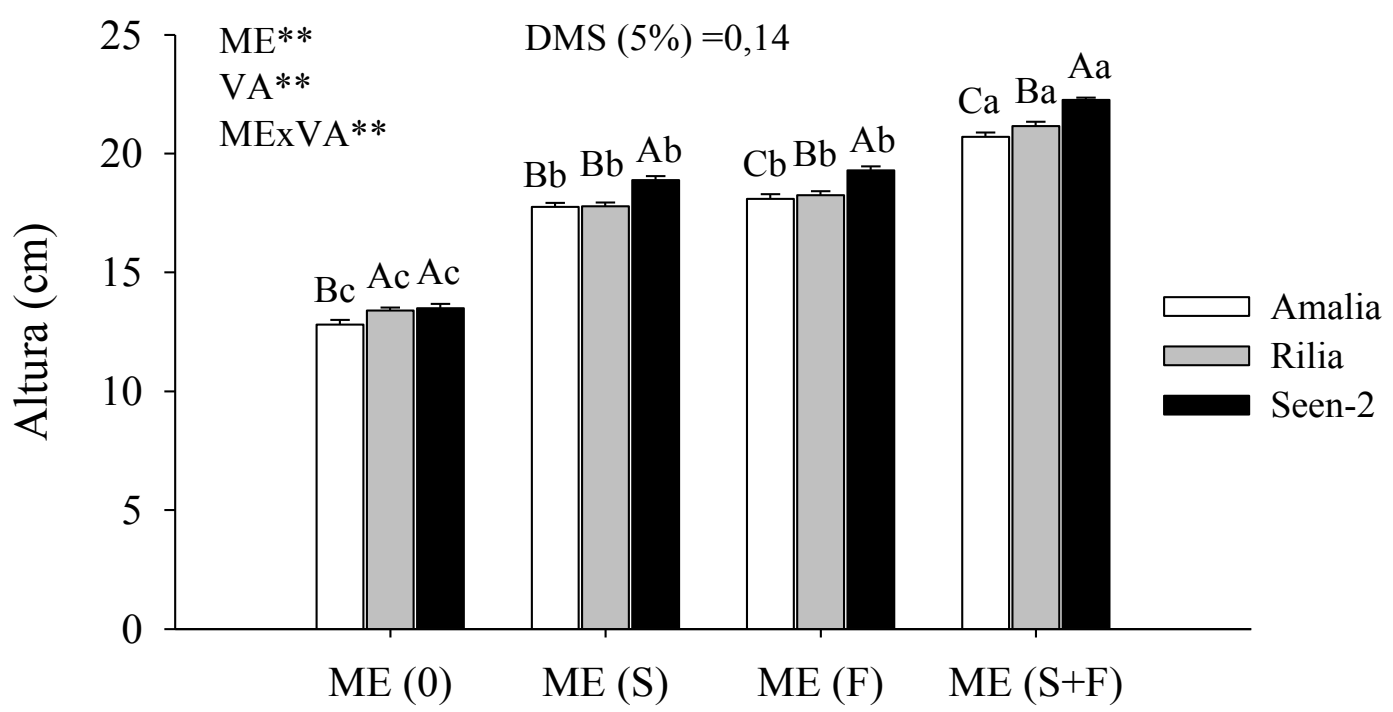

ME (0): sin aplicación; ME (S): inoculación a la Semilla; ME (F), aplicaciones foliares; ME (S+F): inoculación a las Semillas más aplicaciones Foliares. Valores representados por las medias $(n=5) \pm D E$. Letras mayúsculas difieren entre variedades y letras minúsculas entre tratamientos, según Tukey $(\mathrm{P} \leq 0,05)$. ${ }^{* *}$ Significativo al $99,00 \%$ de confiabilidad. Fuente: elaboración propia.

Figura 3. Efecto de los tratamientos en la altura promedio de las plántulas de tomate en las tres variedades Amalia, Rilia y Seen-2.

El número de hojas junto con el diámetro y la altura de plántulas, definen el momento óptimo para el trasplante de las plántulas de tomate. El número de hojas por planta (NHP), presentó efectos significativos $(\mathrm{P} \leq 0,05)$ para la interacción entre las formas de aplicación de ME y las variedades (Figura 4). Las aplicaciones de las diferentes modalidades de ME mostraron diferencias significativas $(\mathrm{P} \leq 0,05)$ y superiores en el NHP respecto al tratamiento sin aplicación para las tres variedades estudiadas. El mejor tratamiento en el incremento del NHP fue la asociación de $\mathrm{ME}(\mathrm{S}+\mathrm{F})$ al mostrar diferencias significativas con las formas de ME (S) y ME (F) y aumentar este indicador en $36,0 \%$ en la variedad Amalia, 41,32\% en la Rilia y 38,0\% en la Seen-2, con relación al tratamiento sin $\mathrm{ME}$.

Este comportamiento se debe a la acción benéfica que realizan los microorganismos en el sistema suelo-planta (rizosfera), los cuales, contribuyen a acelerar la viabilidad de los nutrientes para las plantas y garantizan un mayor crecimiento y desarrollo de las parcelas inoculadas (Pii et al., 2015; Rashid et al., 2016). Por su parte Liriano et al. (2015) con la aplicación de ME individual y combinada con T. harzianum incrementaron el número de hojas y el área foliar de las plántulas de cebolla en relación al control sin aplicación. Este efecto de la inoculación con $\mathrm{ME}$ en el incremento del número de hojas por planta fue verificado en el cultivo de la fresa por Álvarez et al. (2018), mientras que, la aspersión foliar con ME incrementó el NHP en diferentes especies como en tomate (Olivera et al., 2015), tabaco (Calero et al., 2019a) y frijol (Calero et al., 2018; Quintero et al., 2018; Calero et al., 2019b). 


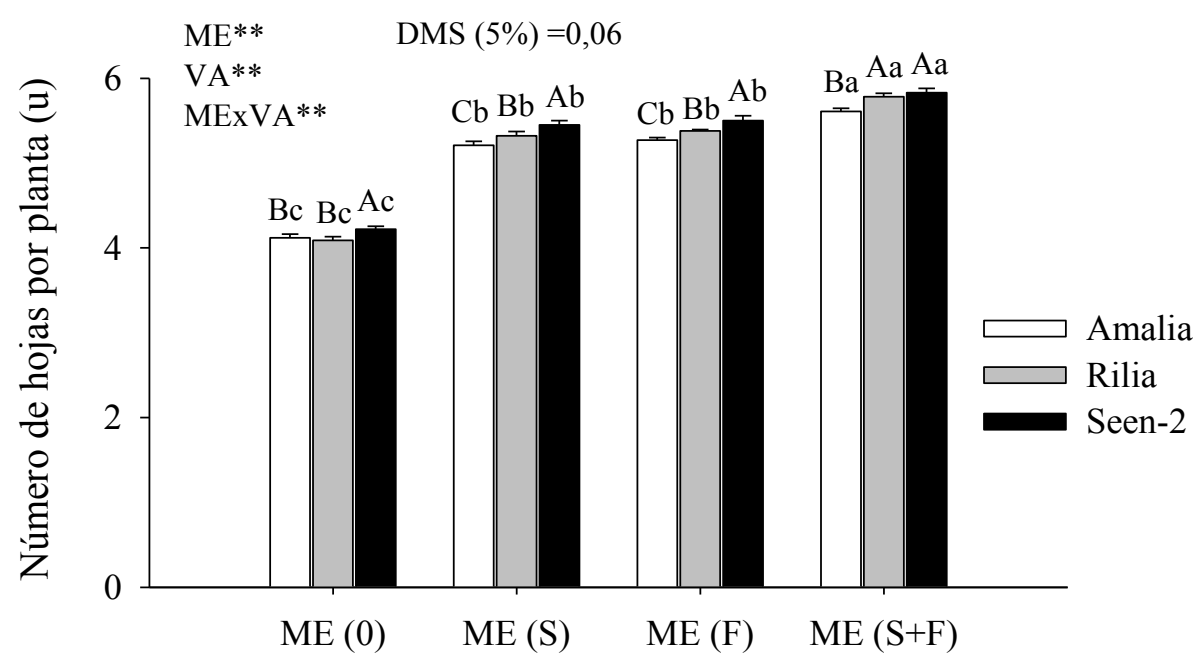

ME (0): sin aplicación; ME (S): inoculación a la Semilla; ME (F), aplicaciones Foliares; ME (S+F): inoculación a las Semillas más aplicaciones Foliares. Valores representados por las medias $(\mathrm{n}=5)$ \pm DE. Letras mayúsculas difieren entre variedades y letras minúsculas entre tratamientos, según Tukey $(\mathrm{P} \leq 0,05)$. ** Significativo al 99,00\% de confiabilidad.

Figura 4. Efecto de los tratamientos en el número de hojas por plántula de tomate en las variedades Amalia, Rilia y Seen-2.

Efectos significativos $(\mathrm{P} \leq 0,05)$ para la interacción entre ME y variedades, fueron detectados en el rendimiento de plántulas $\mathrm{m}^{-2}$. Todos los tratamientos con ME fueron significativas $(\mathrm{P} \leq 0,05)$ y superiores al tratamiento sin la aplicación para las tres variedades (Figura 5). Las mayores producciones fueron alcanzadas cuando se asoció ME (S+F) con diferencias significativas con la aplicación de las formas ME (S) y ME (F) y el tratamiento sin aplicación, con incrementos del $26,0 \%$ en las variedades Amalia y Rilia y de 25,0\% en la Seen-2.

Este trabajo ha demostrado los efectos positivos de la inoculación a las semillas con ME al aumentar los porcentajes de germinación en cuanto a las no inoculadas. La germinación presenta una relación proporcional al rendimiento de plántulas por $\mathrm{m}^{2}$, si ésta aumenta o disminuye, la germinación aumenta o disminuye respectivamente el número de plantas por unidad de área. Resultados satisfactorios con la utilización de ME en el cultivo del tomate, fueron encontrados por Olivera et al. (2015), al estimular el crecimiento y el rendimiento de las plantas, con la aplicación de ME a $25 \mathrm{~mL} \mathrm{~L}^{-1}$ y dos aplicaciones foliares a los 7 y 14 días ddg. Igualmente, se incrementó en 38,00\% la producción de plántulas de tomate y el número de plantas por superficie en comparación con el tratamiento control. 


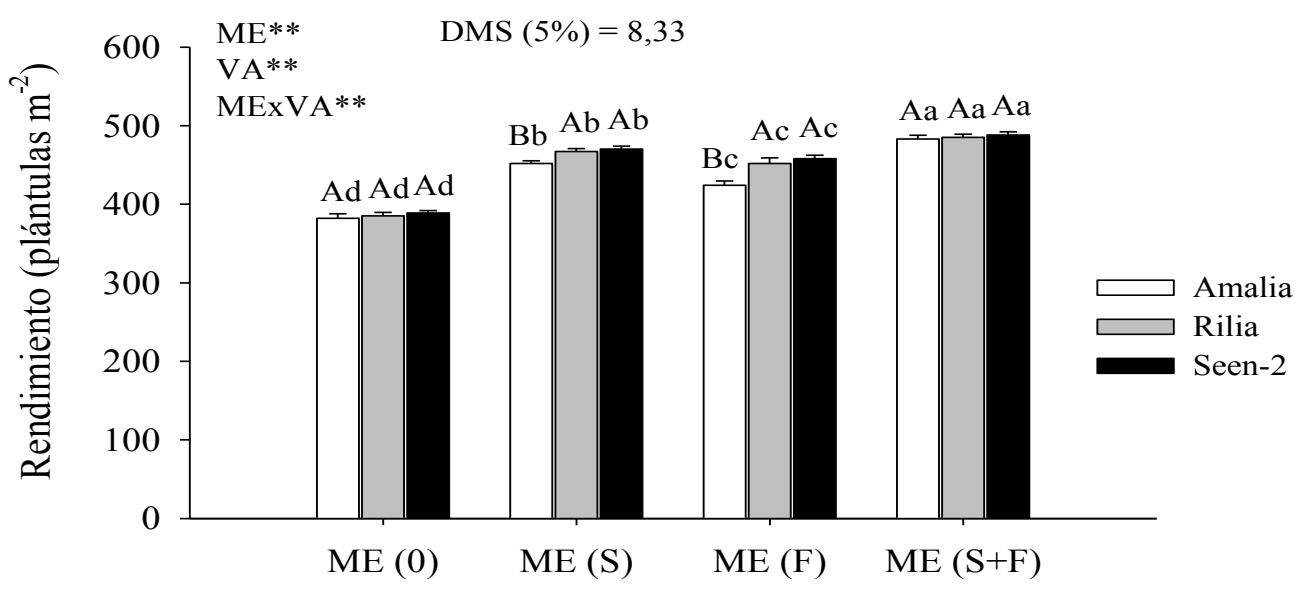

ME (0): sin aplicación; ME (S): inoculación a la Semilla; ME (F), aplicaciones Foliares; ME (S+F): inoculación a las Semillas más aplicaciones Foliares. Valores representados por las medias $(n=5) \pm D E$. Letras mayúsculas difieren entre variedades y letras minúsculas entre tratamientos, según Tukey $(\mathrm{P} \leq 0,05)$. ** Significativo al 99,00 \% de confiabilidad. Fuente: elaboración propia.

Figura 5. Efecto de los tratamientos en el rendimiento de plántulas $\mathrm{m}^{2}$ de tomate en las variedades Amalia, Rilia y Seen-2.

El ciclo de producción de las plántulas de tomate en las tres variedades fue significativo $(\mathrm{P} \leq 0,05)$ y beneficiado por la aplicación de las diferentes formas de ME con relación al tratamiento sin aplicación (Figura 6). El ciclo fue reducido por $\mathrm{ME}$ asociada $(\mathrm{S}+\mathrm{F})$ respecto a las variantes ME (S) y ME (F) individuales y el tratamiento sin $\mathrm{ME}$, con reducciones del 24,0\% en las variedades Amalia y Seen-2 y 22,0\% en la Rilia.

Las comunidades bacterianas dentro de las plantas tienen un gran impacto en la calidad de las plántulas y el rendimiento de las diferentes variedades (Xu et al., 2014). Plántulas poco vigorosas, debilitadas, comprometen todo el desarrollo futuro del cultivo, aumenta su ciclo y en muchos casos, ocasiona pérdidas en la producción (Gómez et al., 2010). El ciclo de producción de las plántulas de tomate fue reducido en cinco días por Olivera et al. (2015) con la concentración de microorganismos nativos multipropósitos de $25 \mathrm{~mL} \mathrm{~L}^{-1}$ y dos aplicaciones foliares a los 7 y 14 días, después de la germinación encontrándose con el testigo sin aplicación. En este sentido, Gómez et al. (2010) consideraron que el 60,0\% del éxito de un cultivo está en obtener plántulas de alta calidad, de ahí la importancia de esta fase inicial antes de la plantación. 


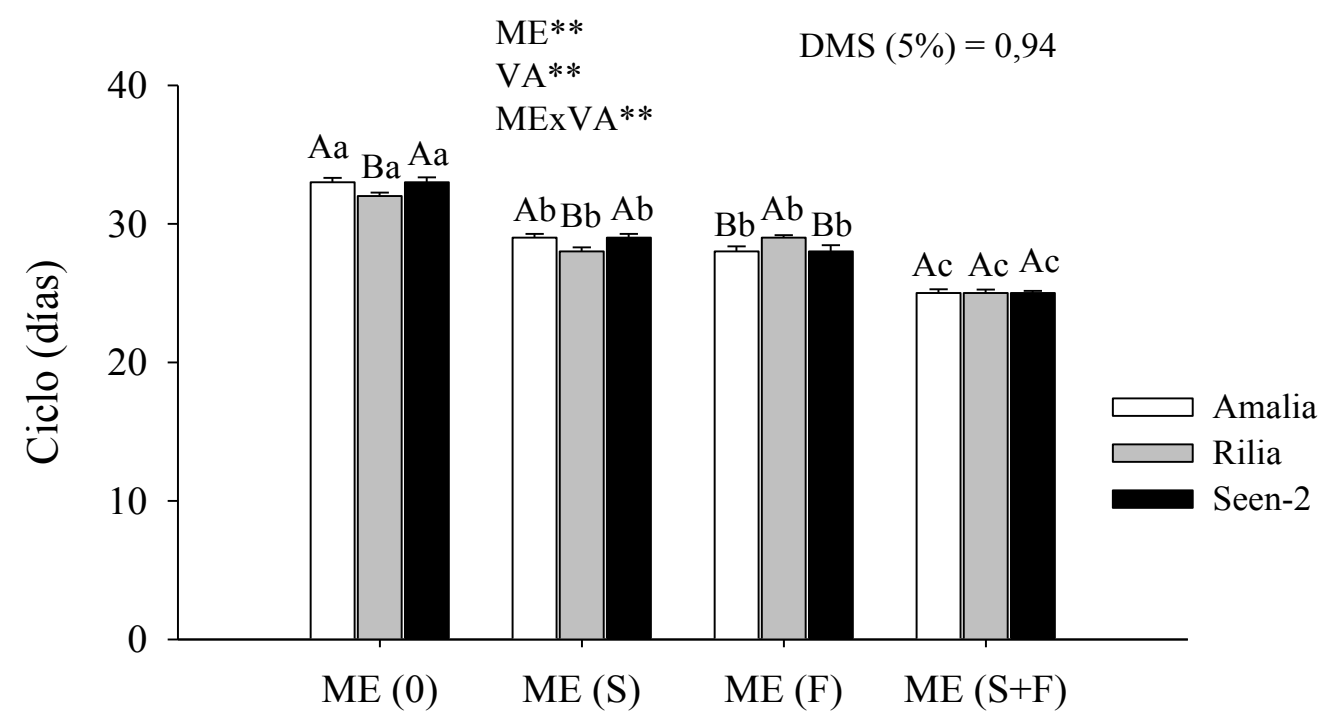

ME (0): sin aplicación; ME (S): tratamiento a la Semilla; ME (F), aplicaciones Foliares; ME (S+F): asociación entre la inoculación a las Semillas más aplicaciones Foliares. Valores representados por las medias \pm DE ( $\mathrm{n}$ $=5$ ). Letras mayúsculas difieren entre variedades y letras minúsculas entre tratamientos, según Tukey (P $\leq 0,05) . * *$ Significativo al $99,00 \%$ de confiabilidad.

Figura 6. Efecto de los tratamientos en el ciclo de producción de plántulas de tomate de las variedades Amalia, Rilia y Seen-2.

\section{CONCLUSIONES}

En las variedades de tomate Amalia, Rilia y Seen2, la inoculación a las semillas más aplicaciones foliares de Microorganismos Eficientes, fueron superiores a los tratamientos individuales y al control sin aplicación. Se logró el incrementó del diámetro, altura de la plántula, el número de hojas y el rendimiento (plántulas $\mathrm{m}^{-2}$ ) con disminución del ciclo de producción de las plántulas.

\section{AGRADECIMIENTOS}

Los autores agradecen a la Sucursal de Labiofam por ofrecer gratuitamente el biofertilizante, al Laboratorio de Biogas de la Universidad de Sancti Spíritus por la caracterización del mismo y a la Empresa de Semillas de Sancti Spíritus por proporcionar las semillas de las tres variedades, para efectuar el desarrollo de estudio. También agradecen a la Cooperativa de Créditos y Servicios "Humberto Castellano", por la disponibilidad de recursos para el acompañamiento del trabajo en campo.

Conflicto de intereses: Los autores declaran que no hay conflicto de interés.

\section{REFERENCIAS BIBLIOGRÁFICAS}

Álvarez, M., Tucta, F., Quispe, E. \& Meza, V. (2018). Incidencia de la inoculación de microorganismos benéficos en el cultivo de fresa (Fragaria sp.). Sci. Agropecu. 9(1): 33-42. doi: 10.17268/sci. agropecu.2018.01.04

Arias, A. (2010). Microorganismos eficientes y su beneficio para la agricultura y el medio ambiente. J. Cienc. E Ing. 2(02): 42-45.

Barbosa, J. \& Maldonado, W. (2015). AgroEstat ${ }^{\circledR}$ : sistema de análises estatísticas para ensaios Agronómicos. Versão 1.1.0.712. Sao Paulo, Brasil: Jaboticabal, Departamento de Ciências Exatas. Universidade Estadual Pualista "Júlio de Mesquita Filho" (Unesp). 
Calero, A., Quintero, E., Olivera, D., Peña, K. \& Pérez, Y. (2019a). Influencia de dos bioestimulantes en el comportamiento agrícola del cultivo del tabaco (Nicotiana tabacum L.). Rev. Fac. Ciencias. 8(1): 31-44. doi: 10.15446/rev.fac.cienc.v8n1.73546

Calero, A., Quintero, E., Pérez, Y., Olivera, D., Peña, K. \& Jiménez, J. (2019b). Efecto entre microorganismos eficientes y fitomas-e en el incremento agroproductivo del frijol. Biotecnol. Sect. Agropecu. Agroindustrial. 17(1): 25-33. doi: 10.18684/bsaa.v17n1.1173

Calero, A., Quintero, E., Olivera, D., Pérez, Y., Castro, I., Jiménez, J. \& López, E. (2018). Respuesta de dos cultivares de frijol común a la aplicación foliar de microorganismos eficientes. Cultiv. Trop. 39(3): 5-10. doi: 10.1234/ct.v39i3.1459

De Mendonça, L., Silva, M., Ceri, D., Bernardi, F. \& Silvia, M. (2013). Avaliação de substratos para a produção de mudas de tomate e pepino. Rev. Ceres. 60(5): 675-682.

Gómez, 0., Morales, 0. \& Laterrot, A. (2010). Mejora genética y manejo de cultivo del tomate para la producción en el Caribe. $1^{\circ}$ ed. La Habana, Cuba: Instituto de Investigaciones Hortícolas "Liliana Dimitrova". 159p.

Hernández, A., Pérez, J., Bosch, D. \& Castro, N. (2015). Clasificación de los suelos de Cuba. $1^{\circ}$ ed. La Habana, Cuba: Ediciones INCA. 93p.

Hernández, R.M., Santacruz, F., Ruiz, M.A., Norrie, J. \& Hernández, G. (2014). Effect of liquid seaweed extracts on growth of tomato seedlings (Solanum lycopersicum L.). J Appl Phycol. 26(1): 619-628. doi: $10.1007 / \mathrm{s} 10811-013-0078-4$

IUSS Working Group, 2015. World reference base for soil resources 2014 (update 2015), international soil classification system for naming soils and creating legends for soil maps. Rome, Italia: FAO. 203p.

Liriano, R., Núñez, D., Hernández, L. \& Castro, A. (2015). Evaluación de microorganismos eficientes y Trichoderma harzianum en la producción de posturas de cebolla (Allium cepa L.). Cent. Agrícola. 42(2): 25-32.
López, E., Unday, Z.G., Henderson, D., Calero, A., Jiménez, J. (2017a). Uso de efluente de planta de biogás y microorganismos eficientes como biofertilizantes en plantas de cebolla (Allium cepa L., cv. 'Caribe-71'). Cultiv. Trop. 38(4): 7-14. doi: 10.1234/ct.v38i4.1397.

López, E., Calero, A., Gómez, Y., Gil, Z., Henderson, D. \& Jiménez, J. (2017b). Efecto agronómico del biosólido en cultivo de tomate (Solanum lycopersicum): control biológico de Rhizoctonia solani. Cultiv. Trop. 38(1): 13-23. doi: 10.1234/ ct.v38i1.1330.

Luna, L., Martínez, R., Hernández, M., Arvizu, S. \& Pacheco, J. (2013). Caracterización de rizobacterias aisladas de tomate y su efecto en el crecimiento de tomate y pimiento. Rev. Fitotec. Mex. 36(1): 63-69.

Luna, M. \& Mesa, J. (2016). Microorganismos eficientes y sus beneficios para los agricultores. Agroecosistemas. 4(2): 31-40.

Nadai, F. B., Menezes, J. B. de C., Catão, H.C., Advíncula, T. \& Costa, C.A. (2015). Produção de mudas de tomateiro em função de diferentes formas de propagação e substratos. Rev. Agro@Mbiente On-Line. 9(3): 261-267. doi: 10.18227/1982-8470ragro.v9i3.2348.

Noh, J., Yam, C., Borges, L., Zúñiga, J. J. \& Godoy, G. (2014). Aislados bacterianos con potencial biofertilizante para plántulas de tomate. Terra Latinoam. 32(4): 273-281.

Núñez, D.B., Liriano, R., Pérez, Y., Placeres, I. \& Sianeh, G. (2017). Respuesta de Daucus carota, L. a la aplicación de microorganismos nativos en condiciones de organopónico. Cent. Agrícola. 44(2): 29-35.

Olivera, D., Ayala, J., Calero, A., Santana, M. \& Hernández, A. (2014). Prácticas agroecológicas en la provincia de Sancti Spíritus, Cuba. Microorganismoseficientes(EM), unatecnología apropiada sobre bases agroecológicas. Ciência Tecnol. Soc. na Construção da Agroecol. 7: 77-83. 
Olivera, D., Leiva, L., Calero, A. \& Meléndrez, J. (2015). Empleo de microorganismos nativos multipropósitos (MNM) en el comportamiento agroproductivo de cultivos hortícolas. Agrotec. Cuba. 39(7): 34-42.

Pedraza, R., Teixeira, K., Fernández,A., de Salamone, I., Baca, B., Azcón, R., Baldani, V. \& Bonilla, R. (2010). Microorganismos que mejoran el crecimiento de las plantas y la calidad de los suelos. Rev. Corpoica Cienc. y Tecnológica Agropecu. 11(2): 155-164. doi: 10.21930/rcta.vol11_num2_art:206.

Pii, Y., Mimmo, T., Tomasi, N., Terzano, R., Cesco, S. \& Crecchio, C. (2015). Microbial interactions in the rhizosphere: beneficial influences of plant growth-promoting rhizobacteria on nutrient acquisition process. A review. Biol. Fertil. Soils. 51(4): 403-415. doi: 10.1007/s00374-0150996-1.

Pinheiro, D.T., Cavalcante, L., Costa, D., Fontes, G., Gama, V., Ferreira, M., Teixeira, F., Teixeira, T. \& Barros, V. (2017). Aspectos tecnológicos e qualitativos da produção de sementes de tomate. Rev. Espac. 38 (34): 10-24.

Quintero, E., Calero, A., Pérez, Y. \& Enríquez, L. (2018). Efecto de diferentes bioestimulantes en el rendimiento del frijol común. Cent. Agrícola. 45(3): 73-80.

Rashid, M.I., Mujawar, L.H., Shahzad, T., Almeelbi, T., Ismail, I.M. \& Oves, M., (2016). Bacteria and fungi can contribute to nutrients bioavailability and aggregate formation in degraded soils. Microbiol. Res. 183: 26-41. doi: 10.1016/j. micres.2015.11.007

Szilagyi, V., Francisco, Á., Ruaro, L. \& Röder, C. (2015). Tomato seedlings growth (Solanum lycopersicum) promoted by bacteria Bacillus amyloliquefaciens subsp. plantarum FZB42 in organic system. Rev. Ciências Agrárias. 38(1): 26-33.

Xu, M., Sheng, J., Chen, L., Men, Y., Gan, L., Guo, S. \& Shen, L. 2014. Bacterial community compositions of tomato (Lycopersicum esculentum Mill.) seeds and plant growth promoting activity of ACC deaminase producing Bacillus subtilis (HYT12-1) on tomato seedlings. World J Microbiol Biotechnol. 30(3): 835-845. doi: 10.1007/ s11274-013-1486-y 